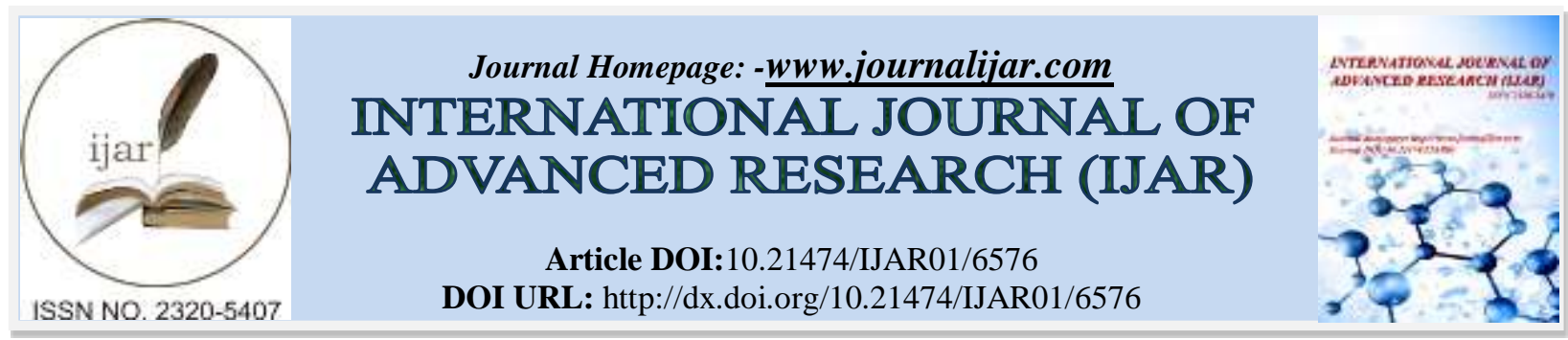

RESEARCH ARTICLE

\title{
INFLUENCE OF CU/IN RATIOS AND THE GROWTH TEMPERATURE ON THE MICROSTRUCTURAL PARAMETERS OF SPRAYED CUINSE 2 THIN FILMS.
}

\author{
Alaa A. Akl ${ }^{1,3}$ and Salah M.M. Salman ${ }^{3,4}$. \\ 1. Physics Department, Faculty of Science, El-Minia University, El-Minia, Egypt. \\ 2. Physics Department, Faculty of Science, Helwan University, Ain-Helwan-Egypt. \\ 3. Physics department, Faculty of Science, Ed Dawadmi, Shaqra University, Saudi Arabia. \\ 4. Educational Services, Qassim University, Ministry of High Education, Saudi Arabia.
}

\section{Manuscript Info}

Manuscript History

Received: 18 December 2017

Final Accepted: 20 January 2018

Published: February 2018

Keywords:-

Spray pyrolysis, X-ray diffraction, Microstructure parameters, $\mathrm{CuInSe}_{2}$ thin films.

\begin{abstract}
In this article, copper indium di-selenide at different ratios of $\mathrm{Cu}$ :In thin films have been grown on heated glass substrates using chemical spray pyrolysis. Characterizations and compositional analysis of $\mathrm{CuInSe}_{2}$ thin films were obtained by X-ray diffraction (XRD) and electron dispersion analysis (EDX). Microstructural parameters as a function of $\mathrm{Cu} / \mathrm{In}$ ratio ranged from 0.9 to 1.1 and the growth temperature $\left(\mathrm{T}_{\text {sub }}\right)$ in the range of $548 \mathrm{~K}$ to $623 \mathrm{~K}$ have been study. Williamson-Hall method has been used to determine the microstructural parameters (crystallite size, microstrain and lattice parameters). X-ray diffraction study confirmed poly-crystalline $\mathrm{CuInSe}_{2}$ thin films with the hexagonal crystal structure having preferential growth along the $\langle 002\rangle$ direction. At the $\mathrm{Cu} / \mathrm{In}$ ratio increased, the crystallite size was found to be increased and decreased with the growth temperature. On the contrary, the microstrain values were decreasing with the growth temperature and $\mathrm{Cu} / \mathrm{In}$ ratio were increasing. Also, the increasing of $\mathrm{Cu} / \mathrm{In}$ ratio leads to improve the degree of crystallization and decrements of both, the lattice parameters and volume of unit cell._ These results are very important in solar cell applications for high efficiency.
\end{abstract}

Copy Right, IJAR, 2018,. All rights reserved.

\section{Introduction:-}

Copper indium di-selenide (CIS) is one of the most promising semiconductor materials used in solar cells in recent years due to its favorable electrical and optical properties, durability and cost effectiveness [1-5]. CuInSe $e_{2}$ is a member of the I-III- $\mathrm{VI}_{2}$ group of semiconductors and exists in the chalcopyrite phase belonging to the zincblende family [4]. Various methods such as molecular been epitaxial (MBE) [6], flash evaporation [7,8], multiple source evaporation [9], single source evaporation [10], RF-sputtering [11], spray pyrolysis [12,13], chemical deposition [14] and stacked elemental layer (SEL) $[15,16]$ have been developed for the synthesis of $\mathrm{CuInSe}_{2}$ thin films.

The photovoltaic (PV) behavior of heterojunction thin film solar cells based CIS depends significantly on its structural characteristics. It have been founds that the CIS thin films possess disordered/ordered structural phase, depending on the growth conditions. The heterojunctions formed from the ordered phase show good (PV) conversion, while the one having disordered phase exhibits very poor response. Therefore, the film growth 
conditions should be adjusts so that the synthesized CIS films corresponding to the ordered phase allows a good $(\mathrm{PV})$ conversion. The direct band-gap $(1.04 \mathrm{eV})$ nature and high absorption coefficient $\left(5 \times 10^{5} \mathrm{~cm}^{-1}\right)[9,13]$ ensures the collection efficiency to be relatively independent of minority carriers diffusion length. Among these methods, chemical spray pyrolysis which presents a gentle, simple and economical method with the advantage of allowing patterned and controlled crystal growth have shown the advantage to control the crystallization engineering of large area $\mathrm{CuInSe}_{2}$ films. Thin films prepared by this method may not be of a very high quality, but are suitable for the studies carried out in this work. In this method it is also possible to prepare mixed thin films of two or more compounds where mixing is perfect since the compounds are mixed in their solution forms. The method of chemical spray pyrolysis is also suitable for the preparation of doped thin films where the percentage of doping materials may be very accurately determined [13,17-20].

The aim of this study is to prepare $\mathrm{CuInSe}_{2}$ thin films using chemical spray pyrolysis technique to design the process equipment as well as establish the experimental conditions needed to produce stoichiometric of CuInSe $\mathrm{C}_{2}$ films. The effect of the growth temperature and $\mathrm{Cu} / \mathrm{In}$ ratios on the microstructure parameters and lattice parameters have been investigated.

\section{Experimental:-}

Reagent grade copper chloride $\left(\mathrm{CuCl}_{2}\right)$, indium chloride $\left(\mathrm{InCl}_{3}\right)$ and $\mathrm{N}-\mathrm{N}$ dimethyl selenourea $(\mathrm{N}-\mathrm{N}-\mathrm{DMSeU})$ were used for preparing the spray solution forming CIS films on glass substrates. Stock solutions $0.025 \mathrm{M}$ of $\mathrm{CuCl}_{2}$, $0.0625 \mathrm{M}$ of $\mathrm{InCl}_{3}$ and $0.165 \mathrm{M}$ of N-N-DMSeU were prepared. Aliquot of these stock solutions were diluted with a constant volume of ethyl alcohol $(25 \mathrm{ml})$ and deionizer water (DI) $(100 \mathrm{ml})$ to have the final concentration of $5 \times 10^{-}$ ${ }^{4} \mathrm{M}$. The solution volumes of $\mathrm{InCl}_{3}$ and $\mathrm{DMSeU}$ were kept constant at $1.00 \mathrm{ml}$ and $1.25 \mathrm{ml}$, respectively, while the solution volume of $\mathrm{CuCl}_{2}$ was varied from $2.25 \mathrm{ml}$ up to $2.75 \mathrm{ml}$ to have the stiochiometric ratio 0.9:1:3.3 up to 1.1:1:3.3. The starting solution was prepared just prior to the commencement of the spraying. This solution was passed through a pneumatic nebulizer with a nozzle diameter $0.7 \mathrm{~mm}$. The spraying process lasted for about $15 \mathrm{sec}$. The period between spraying processes was about 3min; this period is enough to avoid excessive cooling of the glass substrates. The $\mathrm{pH}$ of the solution was maintained constant at 2.35 by adding $\mathrm{HCl}$. The employed solution spray rate was $70 \mathrm{ml} / \mathrm{hr}$ by pre adjusted peristaltic pump. The nitrogen flow rate held constant at $80 \mathrm{ml} / \mathrm{hr}$ by a regulator connected to nitrogen bottle. A temperature controller was used to measure the growth temperature and control the resistance heater via a thermocouple. To prevent dissociation of DMSeU into elemental selenium, all spray depositions were done in dark room.

The film thickness of the prepared samples was kept constant during all the deposition processes at 500nm and was measured by using multiple-beam Fizeau fringes at reflection using either white light or monochromatic light. The colored interference fringes enabled the determination of the order of magnitude of the fringe shift, while the monochromatic fringe shifts as a fraction of order separation have been measured using an eyepiece micrometer.

To investigate the structure of the films, a JEOL X-ray diffractometer (model JSDX-60PA) operating at 40kV and $35 \mathrm{~mA}$ using Ni-filtered $\mathrm{CuK}_{\alpha}$ radiation were employed to obtain diffraction patterns. Continuous scanning was applied with a slow scanning speed $\left(1^{\circ} / \mathrm{min}\right)$ and minor constant $(1 \mathrm{sec})$. A range of $2 \theta$ from $6^{\circ}$ to $72^{\circ}$ was scanned. So that all possible diffraction peaks could be detected. Polycrystalline defect free silicon powder was used for instrumental correction. The chemical compositional elemental analysis of the present samples was investigated by using the energy dispersion analysis of X-ray spectroscopy, EDX. X-ray spectroscope of model Oxford instruments, England was used.

\section{Results and discussion:- Structural properties:-}

XRD patterns of the as-deposited CuInSe 2 films on glass substrates at different growth temperature and $\mathrm{Cu} / \mathrm{In}$ ratio are shown in Figs.(1-3). These patterns ware studied thoroughly to identify the phases expected to be present such as free elemental $(\mathrm{Cu}, \mathrm{In}, \mathrm{Se})$, binary and/ or ternary phases compounds of these elements and their oxides. It is found that all samples, whatever the preparation condition, show four major peaks appeared at $2 \theta=26.64,44.22,52.54^{\circ}$ and $70.92^{\circ}$ have a corresponding to $(112),(204,220),(116,312)$ and $(316,332)$ also the two manor beaks are a subsidiary one appeared at diffracted angles $13.24^{\circ}$ and $24.26^{\circ}$. 


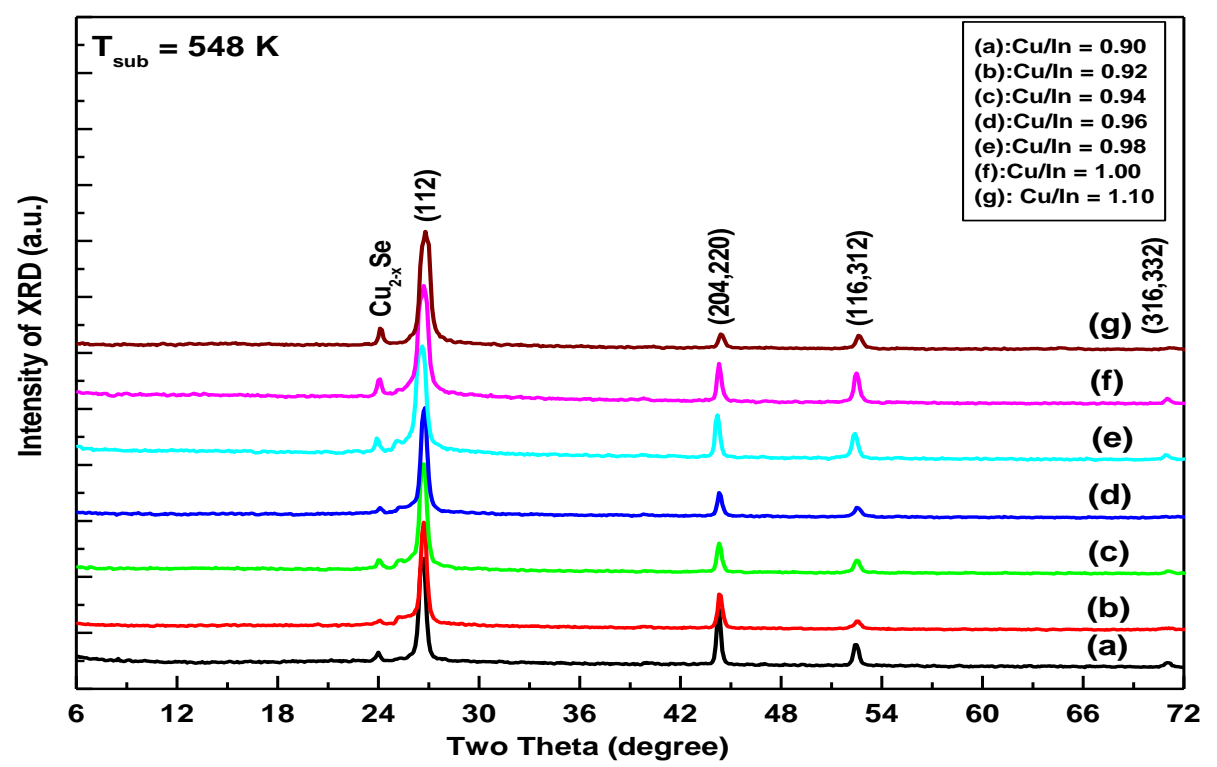

Fig.1:- The x-ray diffractogram of CIS thin films deposited at 548K with different $\mathrm{Cu} / \mathrm{In}$ ratios ranging from 0.90 t0 1.10 .

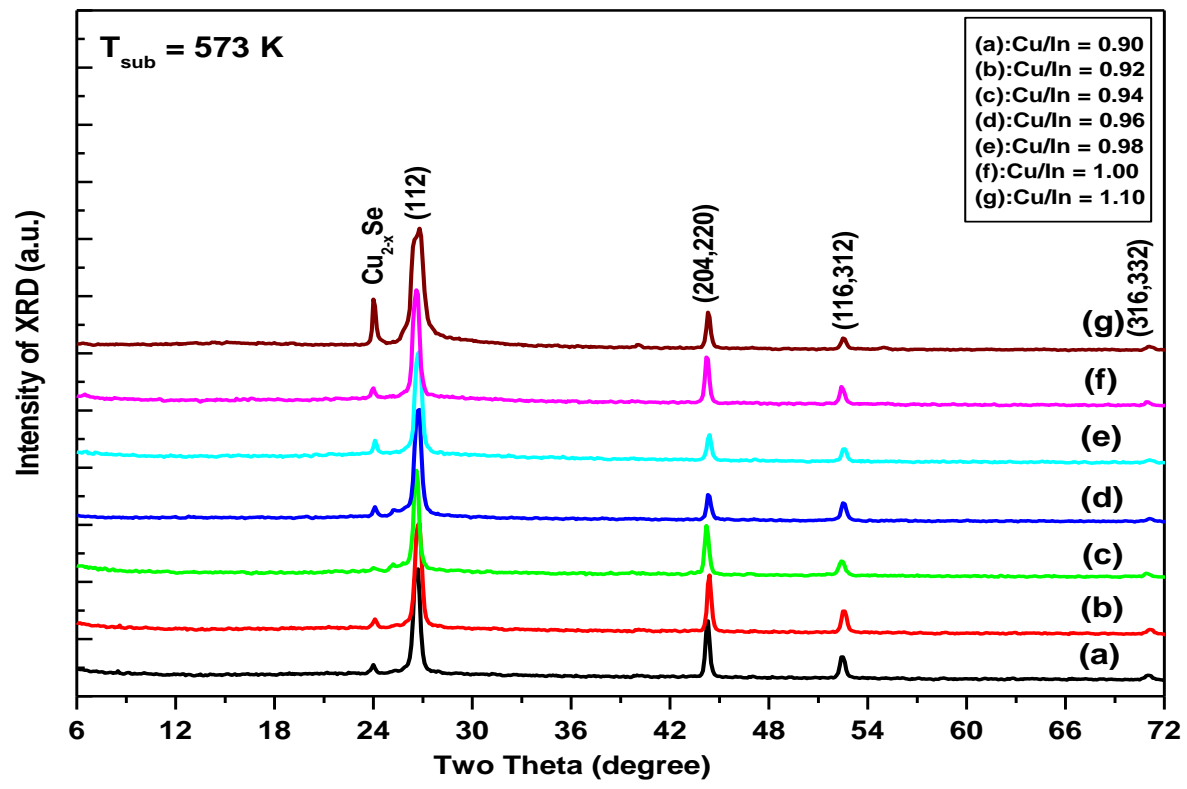

Fig2:- The x-ray diffractogram of CIS thin films deposited at 573K with different $\mathrm{Cu} / \mathrm{In}$ ratios ranging from 0.90 to 1.10 . 


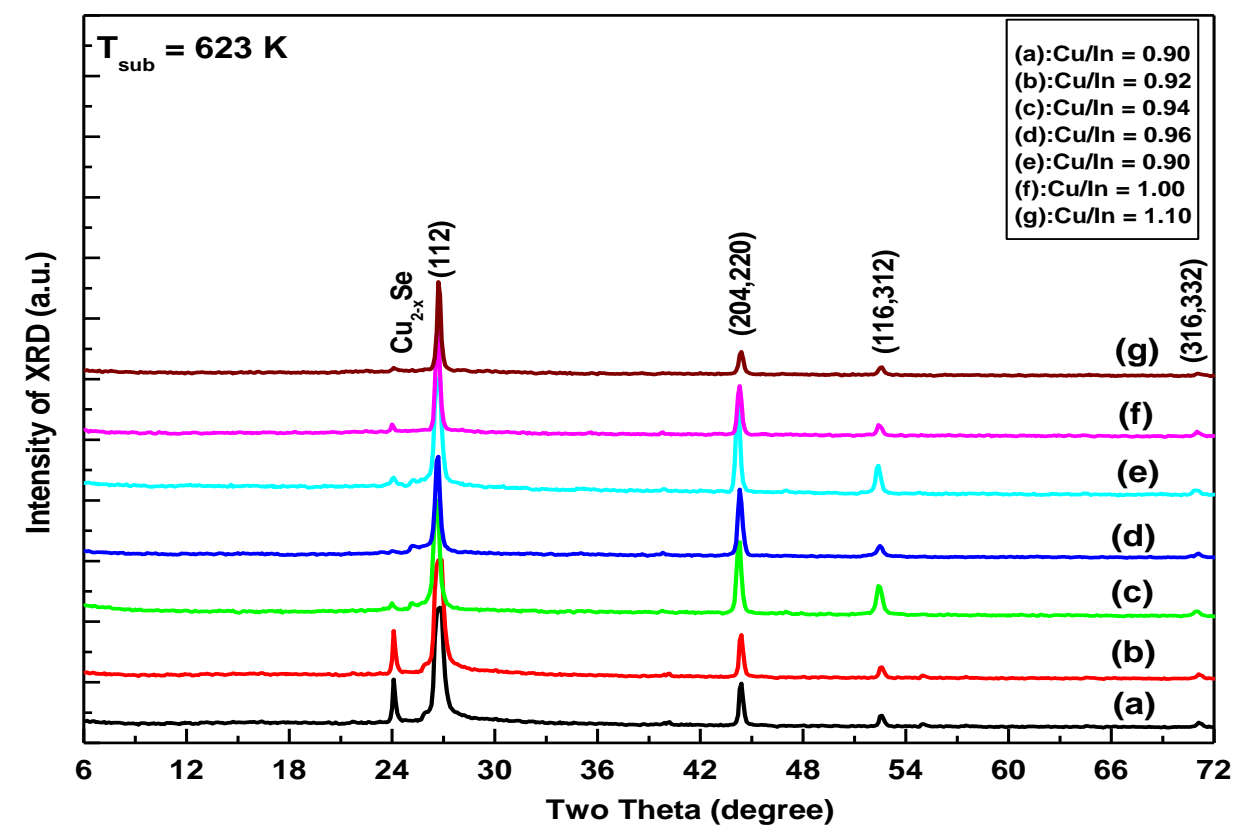

Fig3:- The x-ray diffractogram of CIS thin films deposited at $623 \mathrm{~K}$ with different $\mathrm{Cu} / \mathrm{In}$ ratios ranging from 0.90 to 1.10 .

The sequence and intensity of the major peaks are $(112),(204,220),(116,312)$ and $(316,332)$, are corresponded to $\mathrm{CuInSe}_{2}$ have a tetragonal structure according to the PDF number 80-0535. It is clear that, the spectra are free from the extra peaks that arises formation the phases, elemental, binary or ternary phases and oxide phases. Therefore, it is concluded that, the obtained films are indeed tetragonal chalcopyrite CuInSe $\mathrm{C}_{2}$. XRD peaks intensities and FWHM are varied according to the prepared conditions, but still have the same positions. In addition, the observed high intensity of reflection from the (112) indicates preferred orientation along the $\langle 112\rangle$ direction. The calculated ratio of $\mathrm{I}_{112} / \mathrm{I}_{204}$ for the investigated films is greater than 2.5 at all preparation conditions. It is found that in literature [821-24] for random orientation this ratio should be $\approx 1.5$. This means that the prepared samples are preferentially oriented along the $\langle 112\rangle$ direction. As well as, the two conjugated peaks appeared at $2 \theta=13.24^{\circ}$ and $2 \theta=24.26^{\circ}$ characterizing $\mathrm{Cu}_{2-\mathrm{x}} \mathrm{Se}$ are observed which have a cubic structure. The lattice parameter of $\mathrm{Cu}_{2-\mathrm{x}} \mathrm{Se}$ increases rapidly from $\mathrm{a}=5.741 \pm 0.02 \AA$ for the newly formed phase up to $\mathrm{a}=5.833 \pm 0.02 \AA$ at $623 \mathrm{~K}$.

Thereby, the chalcopyrite phase obtained for the prepared films is independent of both the growth temperature and the $\mathrm{Cu} / \mathrm{In}$ ratios (0.9 to 1.1) in the spray solution. The effect of these parameters is on the microstructure, lattice parameters and their preferential orientation. The structural parameters $(\boldsymbol{a})$ and $(\boldsymbol{c})$ for ternary compound of $\mathrm{CuInSe}_{2}$ thin films of $\mathrm{Cu} / \mathrm{In}$ ratio of range from 0.90 to 1.1 assumed the values: $\mathrm{a}=5.7809 \pm 0.02 \AA$ and $\mathrm{c}=11.5565 \pm 0.04 \AA$ which are very agreement with the value given PDF number 80-0535. These values are slightly less than those reported for single crystal of $\mathrm{CuInSe}_{2}$.

\section{Influence of $\mathrm{Cu} / \mathrm{In}$ on the lattice parameters:-}

Upon a careful consideration to XRD plane at different $\mathrm{Cu} / \mathrm{In}$ ratio, one can observe that there is a slight shift have been taken place towards the higher $2 \theta$-values. It can observed that, the line (112) was shifted from the angle $26.60^{\circ}$ to $26.80^{\circ}$ and the line $(204 / 220)$ was shifted from $44.22^{\circ}$ to $44.40^{\circ}$. Moreover, CuInSe $e_{2}$ of hexagonal structure and has lattice constants $\boldsymbol{a}$ and $\boldsymbol{b}$ equal to $5.781 \AA$ and $\mathrm{c}_{\mathrm{o}}=11.552 \AA$, corresponding to PDF cards No. 80-0535. Consequently, the shift in the position of X-ray diffraction lines can be attributed due to the insertion of $\mathrm{Cu}$ ion which has a small ionic radius in the interstitial spaces between In and Se ions of the $\mathrm{CuInSe}_{2}$ unit cell. Hence, it will cause this observed shift in the position of the X-ray diffraction planes. On the other hand, the value of interplanar spacing, $d$ was calculated from Bragg's law $(\mathrm{n} \lambda=2 \mathrm{~d} \sin \theta)$, while the lattice constants (a) and (c) can be calculated from the lattice geometry equation of the hexagonal structures, which is given as follows [25, 26]:

$$
\frac{1}{d^{2}}=\frac{4}{3}\left(\frac{h^{2}+h k+k^{2}}{a^{2}}\right)+\frac{l^{2}}{c^{2}}
$$


Therefore, and knowing the values of (a) and (c), anyone can be calculated the lattice volume (V) of the unit cell of $\mathrm{CuInSe} \mathrm{e}_{2}$ samples using this simple equation [25,27]:

$\mathrm{V}=(\sqrt{3} / 2) a^{2} c$

When d-values were calculated, it was found that they were slightly decreased with the addition of more $\mathrm{Cu}$ on the account of In, for all diffraction lines. This may be due to the smaller bonding energy value of the Cu-In bond than that of In-Se bond, where these bond energies measure the bond strength and the attractive forces between the sample components. Figures $4 \mathrm{a}, \mathrm{b}$ and $\mathrm{c}$ are described the variation of the lattice parameters and volume of unit cell at different $\mathrm{Cu} / \mathrm{In}$ ratio and growth temperatures.

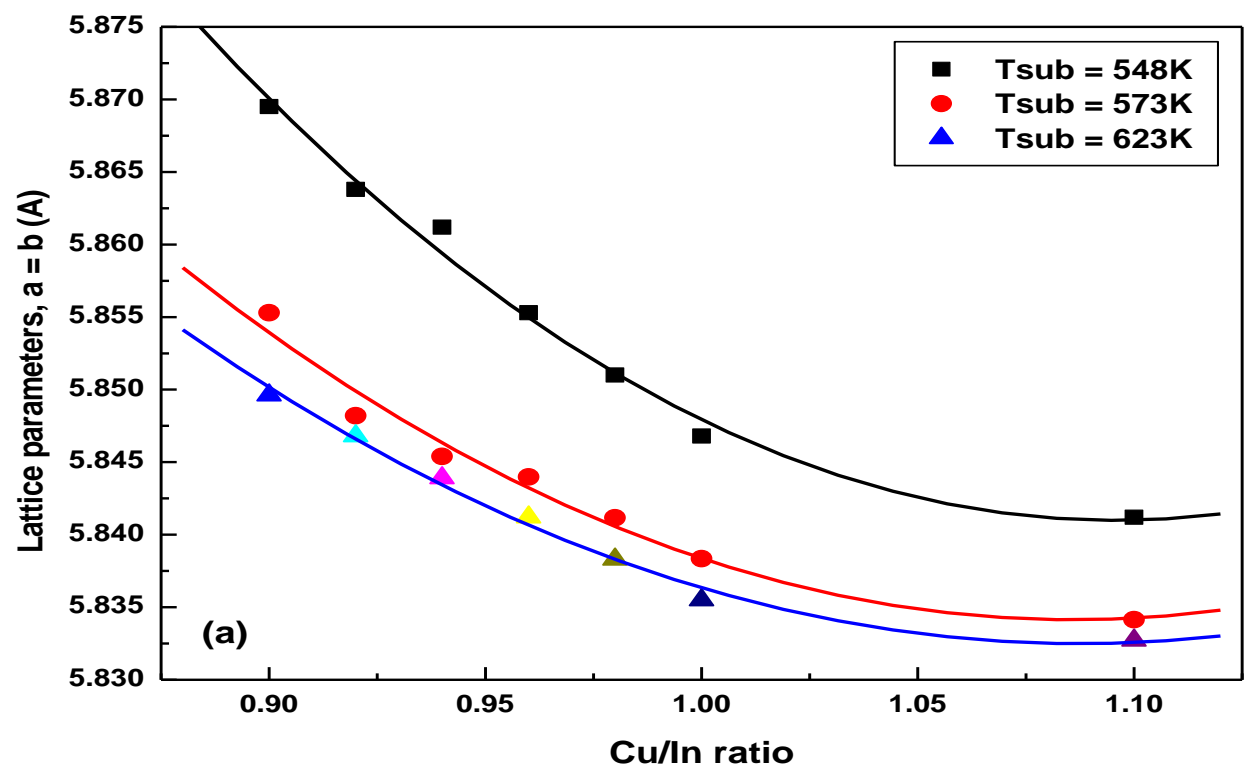

Fig.(4 a):- The lattice parameters, $a=b(\AA)$ as a function of $\mathrm{Cu} / \mathrm{In}$ ratio at different growth temperatures.

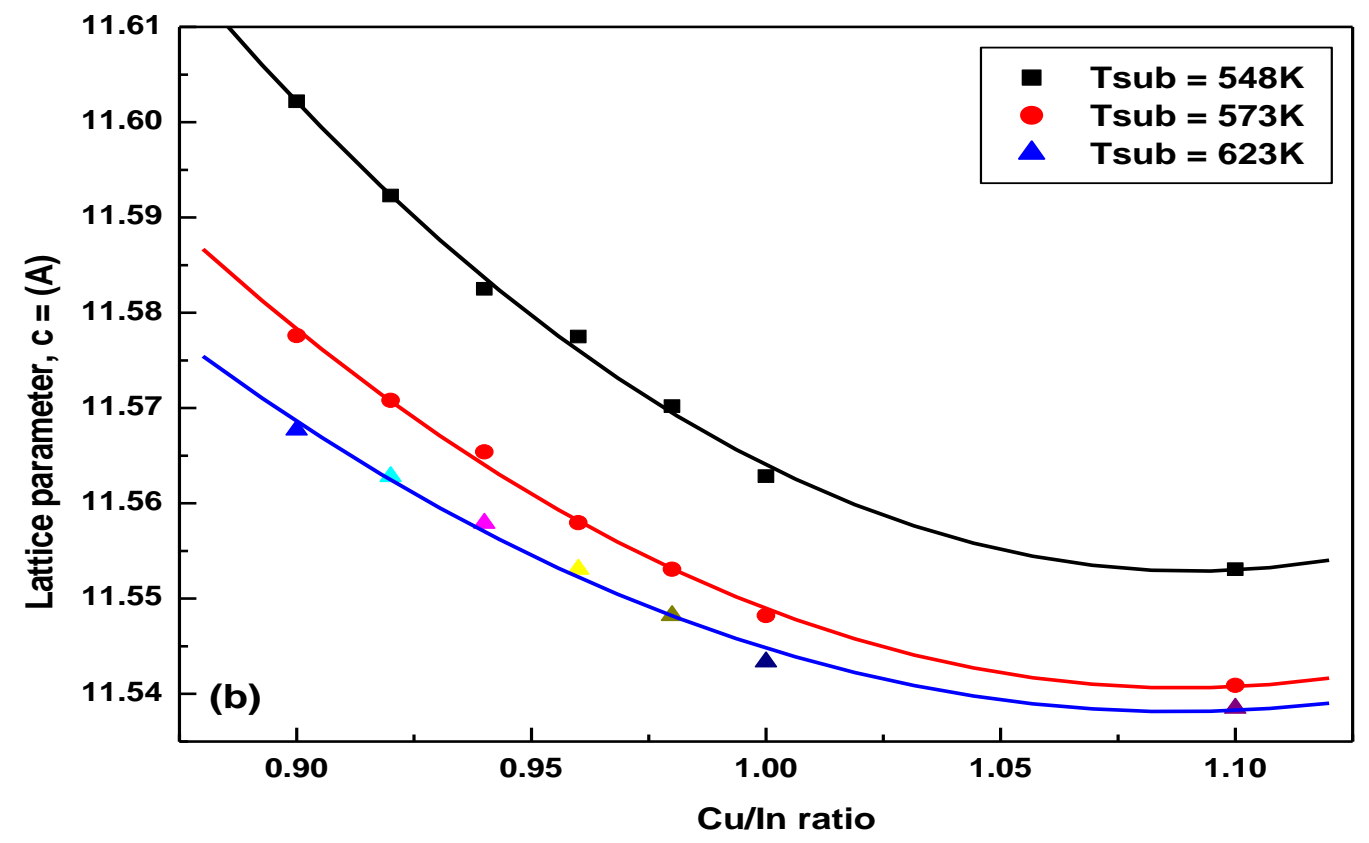

Fig. $(4-\mathbf{b})$ :- The lattice parameters, $c(\AA)$ as a function of $\mathrm{Cu} / \mathrm{In}$ ratio at different growth temperatures. 


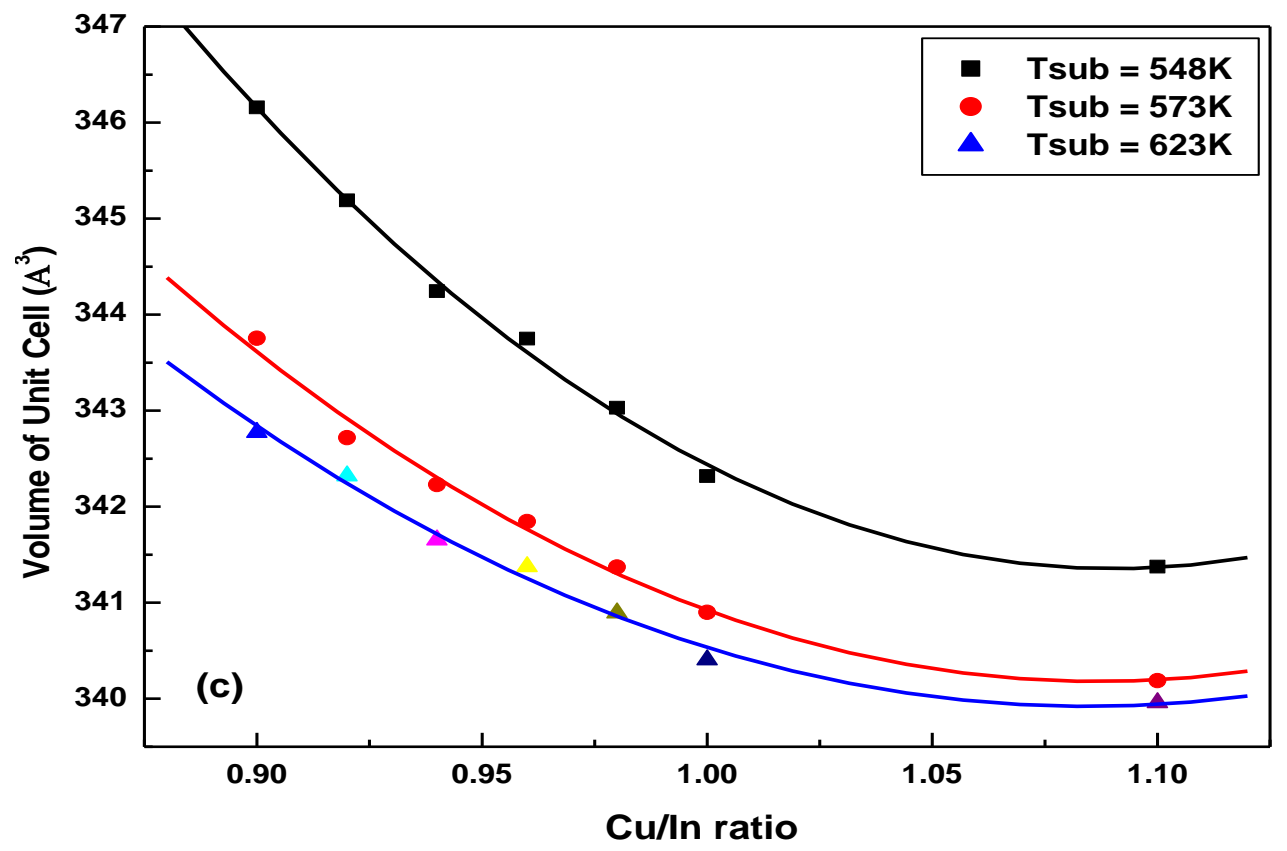

Fig.(4 c):- The volume of unit cells as a function of $\mathrm{Cu} / \mathrm{In}$ ratio at different growth temperatures.

It is clear that, the calculated values of lattice parameters and volume of unit cell were found an outward lattice relaxation of less than $1.7 \%$ around the interstitial, and a larger (up to $3.5 \%$ ) but more localized inward relaxation around the vacancy. Specifically, the original $\mathrm{Cu}-\mathrm{Se}$ bond length of $2.40 \AA$ increases to $2.60 \AA$ (between interstitial $\mathrm{Cu}$ and its nearest Se neighbors). Also, the bond length of In-Se is $2.60 \AA$ augments to $2.65 \AA$ (for In atoms closest to the $\mathrm{Cu}$ interstitial). Around the $\mathrm{Cu}$ vacancy, the lattice experiences a contraction: the edge of the Se tetrahedron

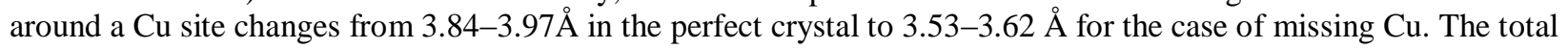
energy of a system with displaced $\mathrm{Cu}$ atom is by merely $3 \mathrm{eV}$ higher than in the perfect crystal [28]. The almost exact agreement with experimental lattice parameters might be accidental for CuInSe $\mathrm{C}_{2}$, but anyway it is a good indication that pseudo potentials and basic functions are appropriately chosen. The $c / a$ ratio remains very close to 2.0 in the chalcopyrite structure $\mathrm{CuInSe}_{2}$, as was the case in both experiment and earlier studies; moreover, the most accurately in all cited calculations.

\section{Preferred orientation and texture coefficient, TC:-}

Preferred orientation is a favorable direction within the texture of materials arises as a result that the material has a strong tendency to be crystallization in a specific direction. If the sample has a texture coefficient value equal the unity $\left(\mathrm{TC}_{(\mathrm{hkl})}=1\right)$ then the crystallites of that sample were randomly oriented. While if the sample has $\mathrm{TC}>1$, then its crystallites were oriented at a certain (hkl) direction [28-31]. The greater value of TC, the greater the number of crystallites that periodically oriented. This coefficient can be obtained using the following equation [28,32-34]:

$$
T C=\frac{N\left(I(h k l) / I_{O}(h k l)\right)}{\sum_{n}\left(I(h k l) / I_{o}(h k l)\right)}
$$

where $\mathrm{I}_{(\mathrm{hkl})}$ is the intensity that is experimentally determined for a specified plane, while $\mathrm{I}_{\mathrm{o}(\mathrm{hkl})}$ is the standard intensity obtained from PDF cards and corresponding to the same plane (hkl). $\mathrm{N}$ is the total number of reflections and $\mathrm{n}$ is the number of diffraction peaks [29]. The calculated values of this coefficient for the three major diffraction lines were listed in Table 1. It was observed that, the diffraction line (112) of the largest intensity (I) was found to have the largest TC value among the other lines of the present CuInSe $e_{2}$ samples. This means that the (112) plane of chalcopyrite structure of $\mathrm{CuInSe}_{2}$ samples is the favorable plane for the growth of small crystallites which have the 
lowest surface energy. Nevertheless, it should that the value of the TC was decreasing with increasing the growth temperature from 1.326 to 1.104 . This means that this plane is the favorable plane for all $\mathrm{Cu} / \mathrm{In} \mathrm{ratios}$. It was observed also that, the lines (204/220) and (116,312) have the lowest intensity and has the smaller TC value. Similar results have been obtained by other authors in the previous literature $[31,35]$.

Table 1:- The calculated values of texture coefficient, $\mathrm{TC}$ of $\mathrm{CuInSe}_{2}$ at different growth temperature and $\mathrm{Cu} / \mathrm{In}$ ratio is $1: 1$.

\begin{tabular}{|c|c|c|c|}
\hline Growth temperature (K) & line (112) & line (204,220) & line (116,312) \\
\hline $\mathbf{5 4 8}$ & 1.326 & 1.124 & 1.002 \\
\hline $\mathbf{5 7 3}$ & 1.178 & 1.016 & 0.861 \\
\hline $\mathbf{6 2 3}$ & 1.104 & 0.974 & 0.675 \\
\hline
\end{tabular}

Determination of the microstructural parameters:-

For each investigated samples prepared of $\mathrm{Cu} / \mathrm{In}$ ratios at different growth temperature, the estimated correct integral broadening $(\beta)$ of the detected X-ray diffraction lines were calculated by the area under the beak divided by the maximum intensity $\left(\mathrm{I}_{\mathrm{o}}\right)$. The correct integral breadth of any examined sample $(\beta)$ is somewhat resulted from the subtraction of two factors, they are the observed broadening, B and instrumental broadening, $b$. The integral breadth of the XRD peak was used to estimate the correct broadening of synthesized $\mathrm{CuInSe}_{2}$ samples [36,37]. There is more than one treatment of the peak, like Lorentzian and Gaussian distribution treatments. According to Gaussian distributions, the correct broadening of the investigated sample is given as:

$$
\beta_{\text {correct }}=\left(\mathrm{B}^{2}{ }_{\text {obs }}-\mathrm{b}^{2}{ }_{\text {ins }}\right)^{1 / 2}
$$

A qualitative description of operative cause of the broadening is presented on the basis of the variation of the profile shape parameter. Finally the mean microstrain and its variation with coherence length were interpreted in terms of local strain and strain derivatives to extract the information regarding the nature of stress confinement in the crystallites. Williamson-Hall's method was used to get the average crystallite size. This method is considered from the most favorite methods, especially in the case of samples that have many X-ray diffraction peaks. Its mathematical equation is given as follows $[28,36,38,39]$ :

$$
\beta_{(\mathrm{hkl})} \cos \theta_{(\mathrm{hkl})}=(\mathrm{k} \lambda / \mathrm{D})+4<\varepsilon>\sin \theta_{(\mathrm{hkl})}
$$

where $\beta_{(\mathrm{hkl})}$ is the estimated correct broadening of the sample, $\theta_{(\mathrm{hkl})}$ is the diffraction angle, $\mathrm{k}$ is the shape factor and in our case, it is equal 0.94 . The incident $\mathrm{X}$-ray wavelength, $\lambda$ is equal $0.154184 \mathrm{~nm}, \mathrm{D}$ is the average crystallite size and $\langle\varepsilon\rangle$ is the average microstrain. Equation (5) of Williamson-Hall method treated the correct pure peak broadening of the sample as it is the sum of the contributions of both the crystallite size and the microstrain that may present in the sample. They supposed that the microstrain that presented in the sample is uniform, i.e. they considered the sample has the isotropic nature. Consequently, and from equation (5), if a graph is plotted between ( $\beta$ $\cos \theta)$ on the $\mathrm{Y}$-axis against $(4 \sin \theta)$ on the $\mathrm{X}$-axis, then a straight line will be obtained [28]. From the intercept part and the slope, it can calculate the average of crystallite size, D and the average of microstrain $\langle\varepsilon\rangle$, respectively. Figs. (5-7) represent the plotting of $(\beta \cos \theta)$ versus $(4 \sin \theta)$ for the present $\mathrm{CuInSe}_{2}$ samples at different growth temperatures. The four-diffraction planes (112), (204), (116) and (316) characterizing the XRD of the deposited films were used for the calculation. The estimated crystallite size as a function of $\mathrm{Cu} / \mathrm{In}$ ratios at different growth temperatures are shown in Fig.(8) and were tabulated in Table 3. 


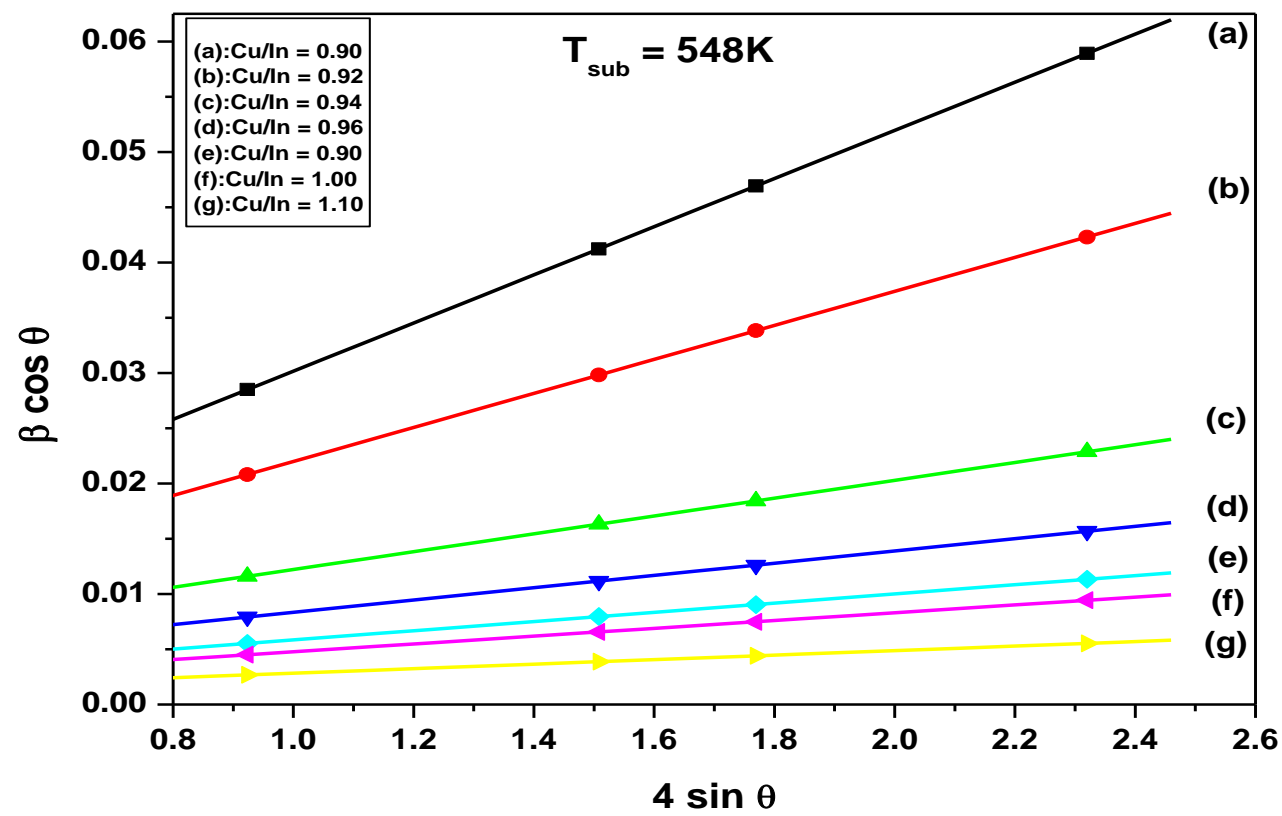

Fig. 5:- Determined the crystallite size and microstrain of $\mathrm{CuInSe}_{2}$ as a function of $\mathrm{Cu} / \mathrm{In}$ ratio at growth temperature of $548 \mathrm{~K}$ by Williamson-Hall's method.

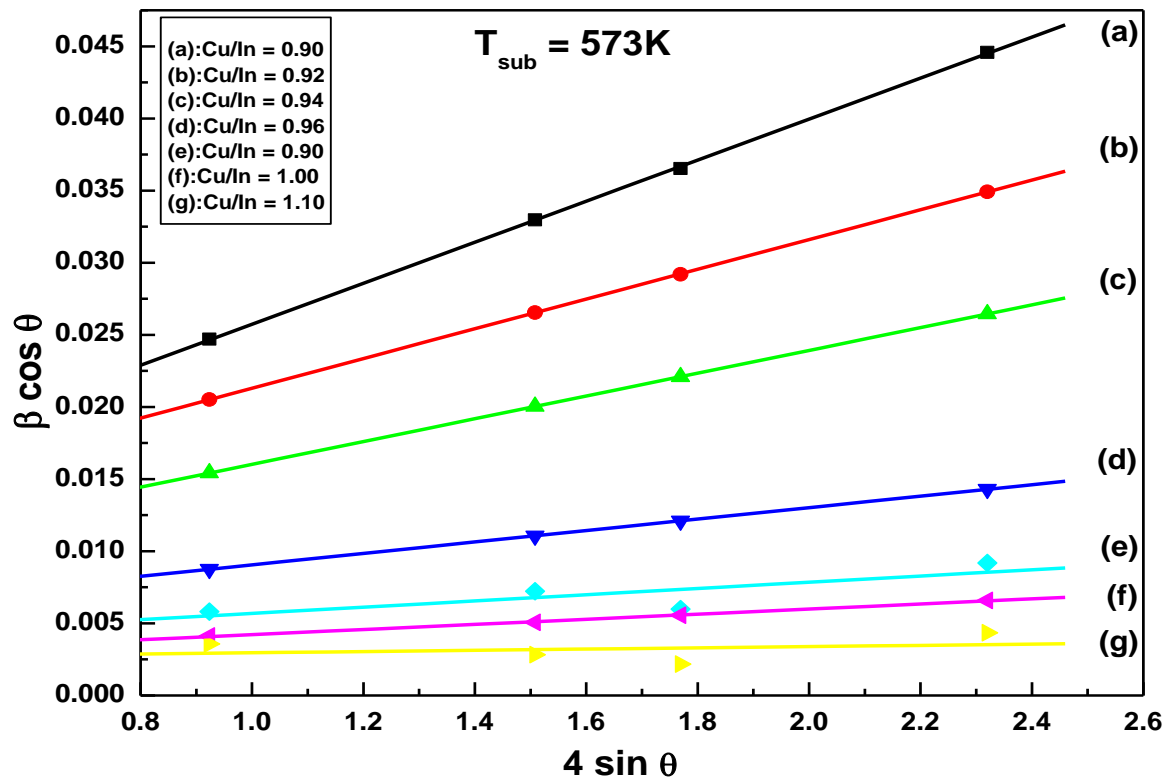

Fig.6:- Determined the crystallite size and microstrain of $\mathrm{CuInSe}_{2}$ as a function of $\mathrm{Cu} / \mathrm{In}$ ratio at growth temperature of $573 \mathrm{~K}$ by Williamson-Hall's method. 


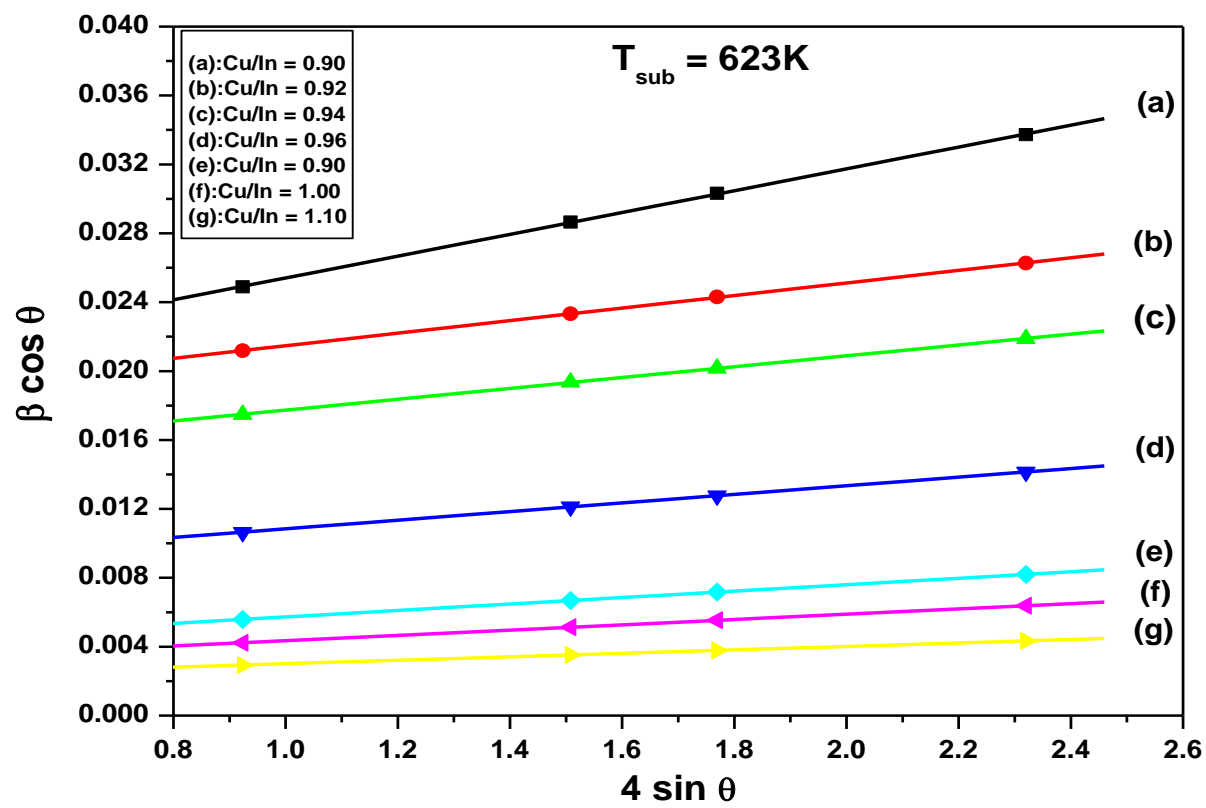

Fig.7:- Determined the crystallite size and microstrain of $\mathrm{CuInSe}_{2}$ as a function of $\mathrm{Cu} / \mathrm{In}$ ratio at growth temperature of $623 \mathrm{~K}$ by Williamson-Hall's method.

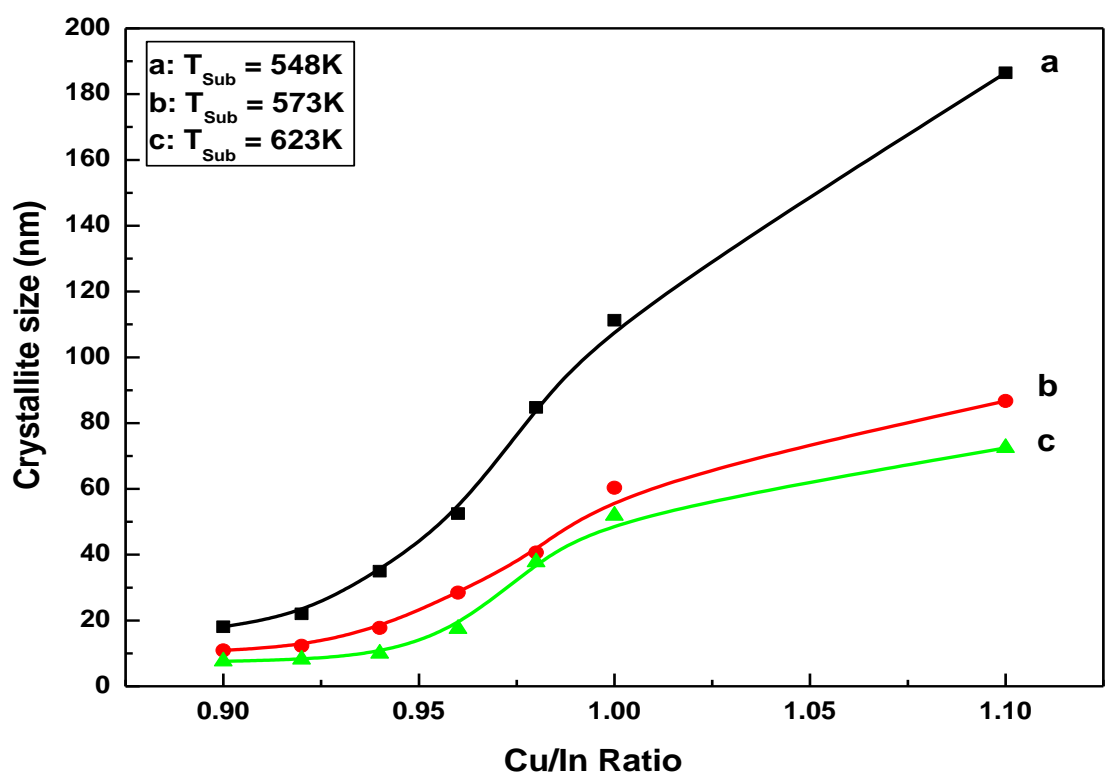

Fig 8:- The crystallite size as a function of $\mathrm{Cu} / \mathrm{In}$ ratios at different growth temperatures.

It is clear that, the crystallite size increases by increasing in both $\mathrm{Cu} / \mathrm{In}$ ratio and growth temperature. This means that the growth under $\mathrm{Cu}$-rich conditions seems favorable to the obtainment of large crystallite size. In contrast, an increase of the indium content leads to the decrease of the crystallite size and the diminution of the deposition rate. Similar behavior of difference in crystallite size between In-rich and $\mathrm{Cu}$-rich of $\mathrm{CuInSe} \mathrm{S}_{2}$ thin films was reported in literature $[13,14,40]$.

Table 2:- The average values of crystallite size (nm) with different of $\mathrm{Cu} / \mathrm{In}$ ratios of CIS films.

\begin{tabular}{|c|c|c|c|}
\hline $\mathbf{C u} / \mathbf{I n}$ ratios & $\mathbf{T}_{\text {sub }}=\mathbf{5 4 8 K}$ & $\mathbf{T}_{\text {sub }}=\mathbf{5 7 3 K}$ & $\mathbf{T}_{\text {sub }}=\mathbf{6 2 3 K}$ \\
\hline $\mathbf{0 . 9 0}$ & 17.27 & 12.46 & 7.65 \\
\hline $\mathbf{0 . 9 2}$ & 22.03 & 13.24 & 8.16 \\
\hline
\end{tabular}




\begin{tabular}{|c|c|c|c|}
\hline $\mathbf{0 . 9 4}$ & 34.96 & 17.73 & 9.95 \\
\hline $\mathbf{0 . 9 6}$ & 52.51 & 28.45 & 17.44 \\
\hline $\mathbf{0 . 9 8}$ & 84.75 & 40.65 & 37.76 \\
\hline $\mathbf{1 . 0 0}$ & 118.26 & 64.35 & 51.86 \\
\hline $\mathbf{1 . 1 0}$ & 186.52 & 86.75 & 72.46 \\
\hline
\end{tabular}

The variations of the microstrain of CIS films as a function of $\mathrm{Cu} / \mathrm{In}$ ratio are depicted in Fig.(9) and Table 3. It is clear that, the microstrain increase with the raising of the $\mathrm{Cu} / \mathrm{In}$ ratio or growth temperature, either which is expected since the atoms, or molecules are ejected from the target source by higher momentum transfer due to ionic collisions. The more power density events with higher kinetic energy that recombine on the substrate surface with higher mobility energy increasing causing microstrain.

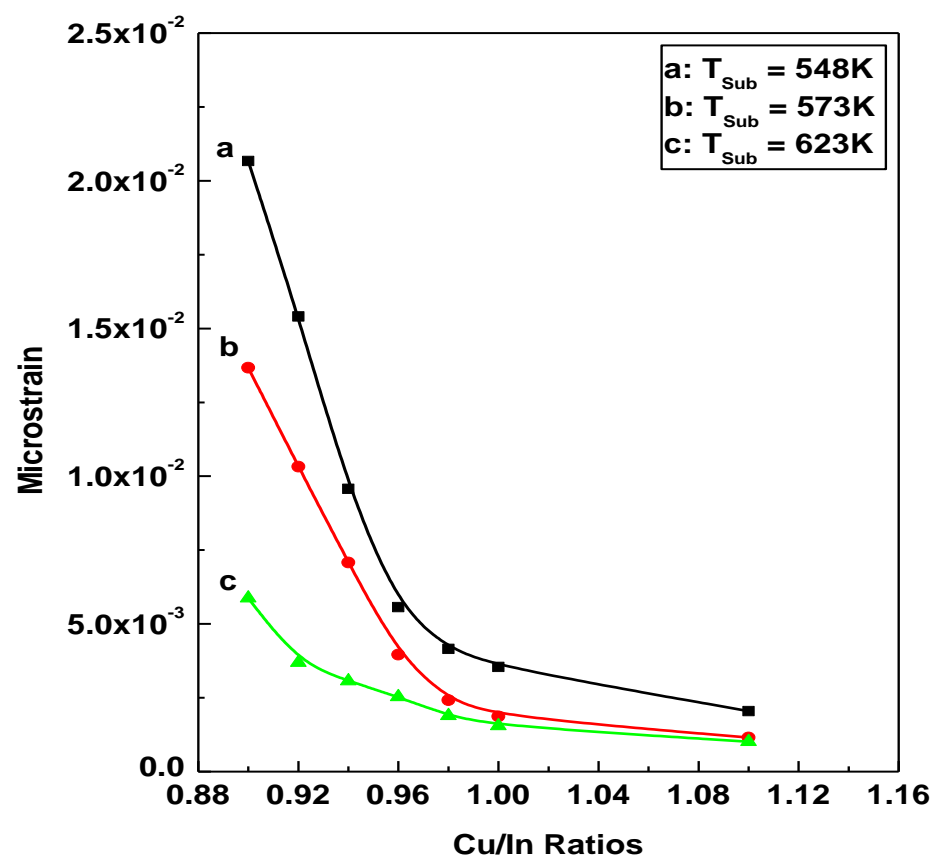

Fig 9:- The microstrain as a function of $\mathrm{Cu} / \mathrm{In}$ ratios at different growth temperatures.

Table 3:- The average values of microstrain with different of $\mathrm{Cu} / \mathrm{In}$ ratios of CIS films at different growth temperature.

\begin{tabular}{|c|c|c|c|}
\hline $\mathbf{C u} / \mathbf{I n ~ r a t i o s}$ & $\mathbf{T}_{\text {sub }}=\mathbf{5 4 8 K}$ & $\mathbf{T}_{\text {sub }}=\mathbf{5 7 3 K}$ & $\mathbf{T}_{\text {sub }}=\mathbf{6 2 3 K}$ \\
\hline $\mathbf{0 . 9 0}$ & $21.78 \times 10^{-3}$ & $14.15 \times 10^{-3}$ & $6.42 \times 10^{-3}$ \\
\hline $\mathbf{0 . 9 2}$ & $15.41 \times 10^{-3}$ & $10.32 \times 10^{-3}$ & $3.69 \times 10^{-3}$ \\
\hline $\mathbf{0 . 9 4}$ & $8.07 \times 10^{-3}$ & $7.88 \times 10^{-3}$ & $3.17 \times 10^{-3}$ \\
\hline $\mathbf{0 . 9 6}$ & $5.57 \times 10^{-3}$ & $3.96 \times 10^{-3}$ & $2.53 \times 10^{-3}$ \\
\hline $\mathbf{0 . 9 8}$ & $4.15 \times 10^{-3}$ & $2.42 \times 10^{-3}$ & $1.89 \times 10^{-3}$ \\
\hline $\mathbf{1 . 0 0}$ & $3.54 \times 10^{-3}$ & $1.87 \times 10^{-3}$ & $1.55 \times 10^{-3}$ \\
\hline $\mathbf{1 . 1 0}$ & $2.05 \times 10^{-3}$ & $1.15 \times 10^{-3}$ & $1.01 \times 10^{-3}$ \\
\hline
\end{tabular}

EDX and the elemental composition analysis;-

The energy dispersive analysis of X-ray or energy dispersive X-ray spectroscopy technique (EDAX, EDX or EDS) is considered a powerful tool used to analyze the elemental constituents of any chemical compound contains more than one element. The elemental composition analysis of the present $\mathrm{CuInSe}_{2}$ samples was examined, thereby the weight and atomic percentages of copper, indium and selenium elements were obtained [40]. Table 4 gives typical compositions of $\mathrm{CuInSe}_{2}$ thin films prepared by spray pyrolysis at different $\mathrm{Cu} / \mathrm{In}$ ratios. 
Table 4:- The elemental composition ratios (atomic and weight percentage) of investigated samples are indicated in atomic percent $\mathrm{Cu}: \mathrm{In}: \mathrm{Se}$.

\begin{tabular}{|c|c|c|c|c|c|c|c|}
\hline \multirow{2}{*}{$\begin{array}{c}\text { Cu/In } \\
\text { ratios }\end{array}$} & \multicolumn{2}{|c|}{ Cu\% } & \multicolumn{2}{c|}{ In\% } & \multicolumn{2}{c|}{ Se\% } & \multirow{2}{*}{ Total } \\
\cline { 2 - 6 } & Weight & Atomic & Weight & Atomic & Weight & Atomic & \\
\hline $\mathbf{0 . 9 0}$ & 17.324 & 23.109 & 34.806 & 25.542 & 47.870 & 51.349 & 100.00 \\
\hline $\mathbf{0 . 9 2}$ & 17.641 & 23.367 & 34.672 & 25.385 & 47.687 & 51.248 & 100.00 \\
\hline $\mathbf{0 . 9 4}$ & 17.956 & 23.678 & 34.539 & 25.183 & 47.505 & 51.139 & 100.00 \\
\hline $\mathbf{0 . 9 6}$ & 18.268 & 24.112 & 34.408 & 25.076 & 47.324 & 50.812 & 100.00 \\
\hline $\mathbf{0 . 9 8}$ & 18.578 & 24.356 & 34.278 & 24.889 & 47.144 & 50.755 & 100.00 \\
\hline $\mathbf{1 . 0 0}$ & 18.885 & 24.689 & 34.148 & 24.787 & 46.967 & 50.524 & 100.00 \\
\hline $\mathbf{1 . 1 0}$ & 20.389 & 25.324 & 33.515 & 24.362 & 46.096 & 50.314 & 100.00 \\
\hline
\end{tabular}

Generally, the elemental analysis using the EDX spectrometer may give an assessment of the sample about $0.1 \%$. Generally, there is a good agreement between the theoretical calculated ratios and those obtained experimentally.

\section{Conclusion:-}

$\mathrm{CuInSe}_{2}$ polycrystalline thin films have been grown at different growth temperature and variation of $\mathrm{Cu} / \mathrm{In}$ ratios prepared by spray pyrolysis. It has been observed that microstructure depend on the preparation conditions, in particular growth temperature and $\mathrm{Cu} / \mathrm{In}$ ratio. Single-phase of CIS thin films with the chalcopyrite structure are obtained regardless the change in $\mathrm{Cu} / \mathrm{In}$ ratio and growth temperature from 0.9 to 1.1 and $548 \mathrm{~K}, 573 \mathrm{~K}, 623 \mathrm{~K}$, respectively. In addition, at higher $\mathrm{Cu} / \mathrm{In}$ ratio are formed of agglomerates of diameter 25 to $200 \mathrm{~nm}$. The crystallite size is increases by rising in both $\mathrm{Cu} / \mathrm{In}$ ratio and growth temperature. This means that the growth under $\mathrm{Cu}$-rich conditions seems favorable to the obtainment of large crystallite size. By modifying the spray parameters it is possible to obtain CIS thin films with chalcopyrite structure and (112) preferred orientation. In addition, the crystallite size was increased as adding more of $\mathrm{Cu}$ element due to the agglomerating of the small crystallites and diminished the free volumes at the boundaries, which support the results that obtained from XRD. Therefore, the increasing the $\mathrm{Cu}$-rich leads to improve the crystallinity nature of the samples and reduces their crystal lattice parameters and volume of unit cell. The results of this work are very distinctive and important in the solar cells devices to develop and increase conversion efficiency as well as photovoltaic applications.

\section{References:-}

1. L.L.Kazmerski, F.R.White and G.K.Morgan, Appl. Phys. Lett.,29(1976)268.

2. J.L.Shay, S.Wagner and H.M.Kasper, Appl. Phys. Lett.,27(1975)89.

3. A.N.Y.Samaan, R.Vaidhyanathn and R.Noufi, Solar Cells,16(1986)181.

4. H.J.Hovel, Semiconductors and Semimetals, Vol.11 (Academic Press, New York, (1985)75.

5. S.B.Moorthy, R.Dhanasekaram and P.Ramasamy, Thin Solid Films, 198(1991)209.

6. G.Salviati and D.Seuret, Thin Solid Films, 104(1983)L75.

7. R.Noufi, A. Mason. and A.Franz, Thin Solid Films, 202 (1991) 299.

8. J.Parkes, R.D.Tomlinson and M.J.Hampshire, J.appl.cryst. (1973) 414.

9. B.D. Cullity, Elements of X-ray diffraction, 2nd ed., Addison-Wesley,California, USA, 1978, p. 102.

10. R.Scheer, K.Diesner and H.J.Lewerenz, Thin Solid Films 268 (1995) 130.

11. M.C.Arraud, F.Ouchen, L.Martin and S.Duchemin, Thin Solid Films 311(1998) 115.

12. K.Subbaramaiah and V.Sundara Raja, Thin Solid Films 208 (1992) 247.

13. Alaa A. Akl a, H.H. Afify, Materials Research Bulletin 43 (2008) 1539.

14. A.Zouaoui, M.Lachab, M.L.Hidalgo, A.Chaffa, C.Llinares and N.Kesri. Thin Solid Films 339(1999) 10.

15. J.R.Tuttle, D.S.Albin and R.Noufi, Solar cells 30 (1991) 21.

16. 16- A.A. Akl, Ph.D.Thesis, El-Minia University, Egypt (1997).

17. A. Zouaoui, M. Lachab, M.L. Hidalgo, A. Chaffa, C. Llinares, N. Kesri, Thin Solid Films 339 (1999) 10.

18. K. Subbaramaiah, V. Sundara Raja, Thin Solid Films 208 (1992) 247.

19. S. Shirakata, T. Terasako, T. Kariya, J. Phys. Chem. Solids 66 (2005) 1970.

20. M.E. Beck, M. Cocivera, Thin Solid Films 272 (1996) 71.

21. Alaa A. Akl, Safwat A. Mahmoud, S.M. AL-Shomar, A.S. Hassanien, Materials

22. Science in Semiconductor Processing 74C (2018) 183-192.

23. C.S. Barret, T.B. Massalski, Structure of Metals, Pergamon Press, Oxford (1980).

24. S. Ilican, Y. Caglar, M. Caglar, J. Optoelectron. and Advanced Materials, 10 (2008) 2578.

25. F. Chouikh, Y. Beggah, M.S. Aida, J Mater Sci: Mater Electron, 22 (2011) 499- 505. 
26. A. Khorsand Zak, W.H. Abd. Majid, M.E. Abrishami, RaminYousefi, Solid State Sciences 13 (2011) 251.

27. B.D. Cullity, Addison-Wesley Publishing Company, Inc., Boston (1979), Elements of X-Ray Diffraction.

28. A.V. Postnikov, M.V. Yakushev; Thin Solid Films 451-452 (2004) 141.

29. A. Singh, H.L. Vishwakarma, Materials Science-Poland, 33, 4 (2015) 751.

30. A.H. Eid, M.B. Seddek, A.M. Salem, T.M. Dahy, Vacuum 83 (2009) 401.

31. Y. Caglar, Journal of Alloys and Compounds 560 (2013) 181

32. B. K. Singh, S. Tripathi, J Mater Sci: Mater Electron, 27 (2016) 2360.

33. Alaa A. Akl, A.S. Hassanien, Inter. J. Advanced Research,2, 11 (2014) 1.

34. Alaa A. Akl, A.S. Hassanien, Superlattices and Microstructures 85 (2015) 67.

35. A.S. Hassanien, Alaa A. Akl, Physica: B 473 (2015) 11.

36. M.V. Yakushev, A.V. Mudryi , V.F. Gremenok, E.P. Zaretskaya, V.B. Zalesski

37. Y. Feofanov, R.W. Martina, Thin Solid Films 451-452 (2004) 133.

38. A.A.S. Akl, A. Ashour, A.A. Ramadan, K. Abd El-Hady, Vacuum 61 (2001) 75.

39. A. Ashour, A.A.S. Akl, , A.A. Ramadan, K. Abd El-Hady, Thin Solid Films 467(2004) 300.

40. B.D. Cullity, Addison-Wesley Publishing Company, Inc., Boston (1979).

41. R. Yogamalar, R. Srinivasan, A.Vinu, K. Ariga, A. C. Bose, Solid State Communications 149 (2009) 1919.

42. A.H. Moharrama, M.M. Harzb, A. Salemc, Applied Surface Science 172 (2001) 